\title{
Pengaruh Elektrifikasi Terhadap Produk Domestik Regional Bruto Per Kapita: Studi Empiris Tahun 2014 - 2019 di Indonesia
}

\author{
Putu Yogi Widyamantara*1, Khoirunnurofik $^{2}$ \\ 1,2Magister Perencanaan Ekonomi dan Kebijakan Pembangunan \\ Universitas Indonesia \\ Jakarta, Indonesia
}

e-mail: yogiwidyamantara@gmail.com¹, khoirunurrofik.rofik@gmail.com²

\begin{abstract}
Abstrak
Riwayat Artikel

Tanggal diajukan:

Penelitian ini mencoba mencari pengaruh elektrifikasi terhadap 17 April 2021 produktivitas. Data yang digunakan adalah data panel pada level kabupaten dan kota dalam rentan waktu 2014-2019. Metode dalam penelitian ini adalah deskriptif kuantitatif dengan data yang digunakan

Tanggal diterima : 3 Mei 2021 merupakan data sekunder berapa data panel PDRB di seluruh Indonesia. Pada penelitian ini produktivitas didekatkan dengan PDRB per kapita. Dari Tanggal dipublikasikan: June 25, 2021 hasil estimasi didapatkan bahwa elektrifikasi berpengaruh positif dan signifikan terhadap pertumbuhan PDRB per kapita pada tahun 2014-2019 secara nasional, Pulau Sumatera, dan Pulau Kalimantan. Adanya elektrifikasi dapat menunjang produktivitas, seperti penerangan, penggunaan mesin yang lebih efisien, peralatan rumah tangga, dan ICT atau komunikasi. Sehingga perlu dilakukan pemenuhan elektrifikasi di Indonesia untuk meningkatkan pertumbuhan PDRB per kapita
\end{abstract}

Kata kunci: rasio elektrifikasi; manfaat elektrifikasi; kabupaten/kota; hak energi; produktivitas.

Pengutipan:

Widyamantara, P.

Y. \&

Khoirunnurofik.

(2021). Pengaruh

Elektrifikasi

Terhadap Produk

Domestik

Regional Bruto

Per Kapita: Studi

Empiris Tahun

2014 - 2019 di

Indonesia. Jurnal

Pendidikan

Ekonomi, 13(1),

31-43

http://dx.doi.org/1

$\underline{0.23887 / i j p e . v 13 i}$

1.33833

\begin{abstract}
This study aims the effect of electrification on productivity. We used data panel on kabupaten dan kota level with 2014-2019 period. The method in this research is descriptive quantitative with the data used is secondary data in the form of GDRB panel data throughout Indonesia In this study, productivity defined as GDRB per capita. Estimation result shows that the electrification ratio has a positive and significant effect to GDRP per capita on 2014-2019 nationally, in Sumatera island, and Kalimantan island. The presence of electrification can support productivity, such as lightning, use of mahines more efficiently, home appliance, and ICT or communication. Therefore, electrification should be fulfilled in Indonesia to increase GDRP per capita growth.
\end{abstract}

Keywords : electrification ratio; benefit of electricity; district/city; energy rights; productivity

\section{PENDAHULUAN}

Energi adalah hak setiap warga negara, hal tersebut menjadi salah satu amanat pemerintah untuk mewujudkan kedaulatan energi kepada masyarakat dalam Undang-Undang Republik Indonesia Nomor 30 tahun 2007 tentang Energi dan Undang - Undang Nomor 30 Tahun 2009 tentang Ketenagalistrikan. UU Nomor 30/2009 menegaskan bahwa tenaga listrik mempunyai peran yang sangat penting dan strategis dalam mewujudkan tujuan pembangunan nasional.

Adanya akses terhadap energi listrik dapat memicu penggunaan peralatanperalatan yang membutuhkan listrik sebagai sumbernya. Berdasarkan hasil klarifikasi, terdapat empat manfaat elektrifikasi. Pertama, adanya penerangan sebagai sarana untuk mempermudah indra mata 
melihat suatu objek yang sebelumnya gelap tidak terlihat menjadi terang akibat mata menangkap cahaya. Dengan adanya penerangan akan meningkatkan atau mempermudah pergerakan karena adanya visibilitas terhadap lingkungan sekitar. Kedua, penggunaan Mesin seperti mesin pabrik, kulkas, oven, smelter. Adanya mesin dapat meningkatkan produksi suatu perusahaan dan dapat menurunkan biaya produksi dengan mengganti pekerja buruh dengan karena adanya automasi peralatan di pabrik selain itu juga menciptakan sektor bisnis kecil. Ketiga, penggunaan peralatan rumah tangga seperti peralatan masak, setrika, kipas angin, mesin cuci bertenaga listrik dapat dilakukan secara cepat dan efisien dengan kehadiran peralatanperalatan listrik. Keempat, penggunaan komunikasi dan ICT (TV, Radio, pemancar, handphone, dll): yang memerlukan daya listrik dapat memicu penggunaan digitalisasi atau internet.

Dari pemanfaatan peralatan listrik tersebut dapat meningkatkan produktivitas masyarakat. Secara teoritis, dalam teori produksi, model persamaan produksi CobbDouglas yang kerap dijadikan referensi untuk menggambarkan pengaruh teknologi terhadap produktivitas. Adanya akses listrik akan memicu penggunaan teknologi untuk meningkatkan output baik untuk mempercepat proses atau penghematan waktu, energi, dan penggunaan bahan baku dalam produksi. Stern and Cleveland (2004) memasukan energi sebagai faktor input kedalam fungsi produksi, dan hasilnya mengindikasi bahwa energi merupakan faktor kunci dalam pertumbuhan. Meningkatnya produktivitas seseorang akan memicu pertumbuhan ekonomi (Jajri \& Ismail, 2010; Suryadi, 2001; Suryani, 2006). Sehingga dibutuhkan ketersediaan energi yang cukup, pendistribusian energi yang merata dan pemanfaatan energi listrik yang baik serta terjangkau dapat mendukung pemenuhan kebutuhan dasar dan meningkatkan kualitas hidup.

Di Negara U.S. berdasarkan historikal roll-out elektrifikasi yang meningkat dari $10 \%$ hingga hampir $100 \%$ selama 3 decade dari tahun 1930 - 1960, menyatakan elektrifikasi memicu peningkatan tenaga kerja agrikultur, populasi, dan nilai properti namun impaknya kecil terhadap ekonomi agrikultur lokal, manfaatnya melebihi biaya historis, bahkan di pedesaan yang memiliki kepadatan penduduk yang rendah, desa yang mendapat akses listrik lebih awal, mendapatkan peningkatan pertumbuhan ekonomi selama beberapa dekade sampai desa tersebut mendapat akses listrik secara penuh. Selain itu elektrifikasi juga memicu ekspansi suburban. Di Benua Amerika, beberapa penelitian mengenai rasio elektrifikasi diantaranya dilakukan oleh Schurr (1982), Jorgenson (1984) yang menunjukkan bahwa elektrifikasi khususnya pada industri di U.S. menyebabkan adanya pertumbuhan output dan produktivitas, Schurr (1982) mengatakan elektrifikasi berkontribusi dalam technological progress yang mana merupakan faktor utama pendukung peningkatan produktivitas dan output. Beberapa penelitian yang mendukung hasil tersebut adalah Lipscomb (2013), Sebastian (2020). Pada Benua Eropa, yang banyak negaranya termasuk negara maju, sulit ditemukan penelitian tentang pengaruh elektrifikasi pada periode terbaru, sama halnya dengan U.S., adanya akses listrik dapat meningkatkan produktivitas di Benua Eropa sesuai dengan buku Electrifiying Europe yang telah ditulis oleh Lagenjik (2008) buku tersebut memaparkan mulai dari awal akses listrik hingga bagaimana listrik dapat mempengaruhi produktivitas pada benua tersebut. Adanya akses listrik juga menunjukkan peningkatan produktivitas di Benua Afrika (Dinkelman, 2011; Kyriakarakos et al., 2020). Elektrifikasi mempunyai dampak yang positif terhadap produktivitas agrikultur yang dilakukan oleh Khandker (2013) di Vietnam Barnes \& Binswanger (1986) di India. Sedangkan di Indonesia, adanya akses listrik juga menunjukkan peningkatan terhadap produktivitas (Best \& Burke, 2018; Burke \& Kurniawati, 2018; Kassem, 2018) .

Pencapaian adanya penggunaan listrik di suatu daerah digambarkan dalam bentuk rasio elektrifikasi. Rasio elektrifikasi adalah perbandingan antara rumah tangga yang telah memiliki listrik terhadap total rumah tangga yang ada di suatu daerah. Jadi bila semua rumah tangga sudah berlistrik maka rasio elektrifikasi menjadi 
$100 \%$, dengan adanya akses listrik kepada seluruh lapisan masyarakat maka diharapkan berperan positif dalam meningkatkan pertumbuhan ekonomi maupun kesejahteraan masyarakat. Pada grafik berikut dapat dilihat peningkatan PDB per kapita dari tahun ke tahun sejalan dengan konsumsi listrik akibat akses listrik yang kian meningkat.

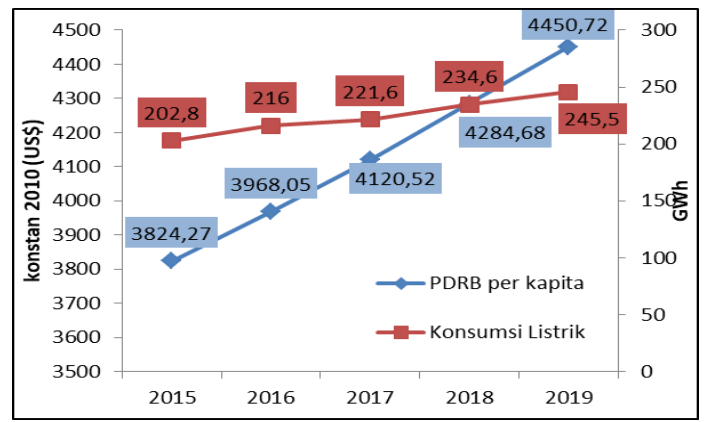

Gambar 1. PDB Per Kapita dan Konsumsi

Listrik di Indonesia 2015 - 2019

Sumber (telah diolah kembali) : PDB Per Kapita (World bank), Konsumsi Listrik (PLN)

Dilihat dari peran energi listrik terhadap kehidupan tersebut maka dalam RPJMN (Rencana Panjang Jangka Menengah Nasional) 2015-2019 dan Rencana Strategis Kementerian Energi dan Sumber Daya Mineral (ESDM) 2015-2019. Target Rasio Elektrifikasi adalah sebagai berikut:

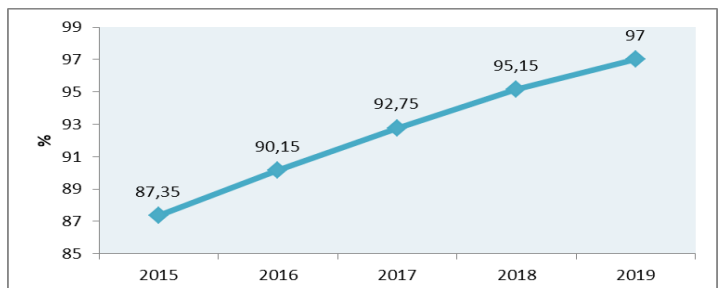

Gambar 2. Target Rasio Elektrifikasi 2015 2019

Sumber: Kementerian ESDM (telah diolah kembali)

Dari impak yang telah dihasilkan, perlu diketahui besaran peranan yang diberikan akibat adanya peningkatan akses listrik atau elektrifikasi. Namun sepanjang pengetahuan penulis, belum ada penelitian kuantitatif yang dilakukan menemukan pengaruh elektrifikasi terhadap produktivitas menggunakan level Kabupaten dan Kota pada tahun 2014 -2019 di Indonesia dengan menggunakan PDRB per kapita untuk pendekatan produktivitas. Oleh sebab itu tujuan dalam penelitian ini adalah mengetahui pengaruh elektrifikasi dan tenaga kerja pada sektor primer, sekunder dan tersier terhadap PDRB per kapita selama tahun 2014 - 2019 untuk tingkat nasional dan menurut pulau, menguji pengaruh konsumsi listrik terhadap PDRB per kapita selama tahun 2014 - 2019 tingkat nasional dan menurut pulau serta mendapatkan rekomendasi untuk kondisi elektrifikasi di Indonesia saat ini. Hipotesis yang diajukan dalam penelitian ini adalah elektrifikasi berpengaruh positif dan signifikan terhadap PDRB per kapita di Indonesia.

\section{METODE}

Penelitian ini menggunakan data panel tahun 2014 - 2019 pada level Kabupaten dan Kota di Indonesia. Metode dalam penelitian ini adalah deskriptif kuantitatif dengan data yang digunakan merupakan data sekunder. Variabel dependen adalah logPDRB perkapita sedangkan variabel independen adalah elektrifikasi(\%), logkons, susut(\%), share tenaga kerja memiliki ijazah SMA (Univ), jumlah tenaga kerja per sektor primer, sekunder, dan tersier (logTK).

Dalam penelitian ini, metode estimasi yang akan digunakan untuk menjelaskan hubungan antara digitalisasi dengan produktivitas tenaga kerja adalah melalui regresi fixed effect atau disebut juga Least Square Dummy Variable (LSDV). Berdasarkan variabel - variabel yang telah dijelaskan sebelumya dengan mengacu pada Best \& Burke (2018), Burke \& Kurniawati (2018) dan beberapa studi terdahulu, maka model persamaan empiris dalam penelitian ialah:

\footnotetext{
logPDRBperkapita ${ }_{i t}=\beta_{0}+\beta_{1} R_{i t}+\beta_{2}$ logKons $_{i t}+\beta_{3}$ Susut $_{i t}$ $+\beta_{4}$ Univit $_{\text {it }}+\beta_{5}$ TKx $_{\text {it }}+$ $\mathbf{e}_{\text {it }} \quad$ (1)

Penelitian ini dilakukan dalam tiga tahap yaitu: secara nasional, 5 pembagian pulau seperti tabel 1 , dan menurut jenis daerah kabupaten atau kota
} 
Tabel 1. Pembagian Kelompok Penelitian

\begin{tabular}{|c|c|c|}
\hline No & Kelompok & Provinsi \\
\hline 1 & Sumatera & $\begin{array}{l}\text { Aceh, Sumatera Utara, Sumatera Barat, Riau, Sumatera Selatan, } \\
\text { Bengkulu, Bangka Belitung, Lampung, Jambi dan Kepulauan Riau }\end{array}$ \\
\hline 2 & Jawa & $\begin{array}{l}\text { Banten, DKI Jakarta, Jawa Barat, Jawa Tengah, Jawa Timur, D.I } \\
\text { Yogyakarta, dan Bali }\end{array}$ \\
\hline 3 & Kalimantan & $\begin{array}{l}\text { Kalimantan Barat, Kalimantan Utara, Kalimantan Tengah, } \\
\text { Kalimantan Timur, dan Kalimantan Selatan }\end{array}$ \\
\hline 4 & Sulawesi & $\begin{array}{l}\text { Sulawesi Utara, Sulawesi Tengah, Sulawesi Selatan, Sulawesi } \\
\text { Tenggara, Gorontalo, dan Sulawesi Barat }\end{array}$ \\
\hline 5 & $\begin{array}{l}\text { Maluku, Papua } \\
\text { dan Nusra }\end{array}$ & $\begin{array}{l}\text { Maluku, Maluku Utara, Papua, Papua Barat, Nusa Tenggara Timur } \\
\text { dan Nusa Tenggara Barat }\end{array}$ \\
\hline
\end{tabular}

Secara deskriptif hubungan PDRB per kapita dan Elektrifikasi dapat dilihat pada gambar 1 .

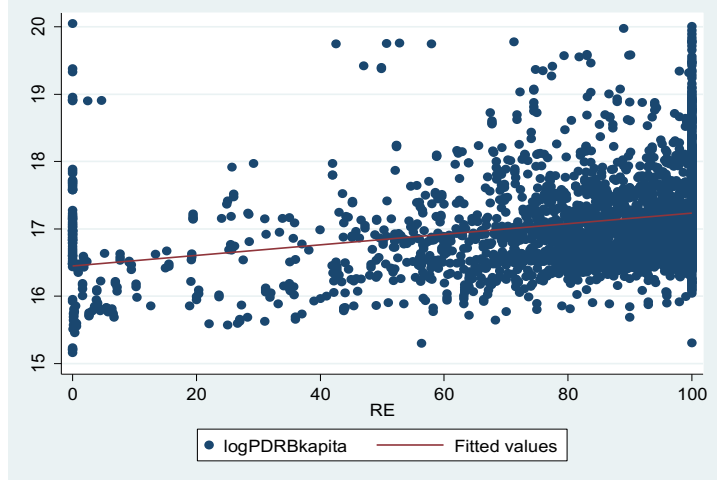

Gambar 3. Hubungan logPDRBperkapita terhadap Elektrifikasi tahun

2014 -2019 di setiap Kabupaten dan Kota

Pada gambar 1 dapat dilihat bahwa garis $Y$ axis merupakan logPDRB perkapita dan $X$ axis merupakan elektrifikasi, pada gambar tersebut garis merah sedikit lebih tinggi saat elektrifikasi lebih besar, secara kasat mata maka elektrifikasi semakin mendekati $100 \%$ maka pertumbuhan PDRB per kapita akan naik. Sedangkan pengaruh susut terhadap pertumbuhan
PDRB per kapita dapat dilihat pada gambar 2.

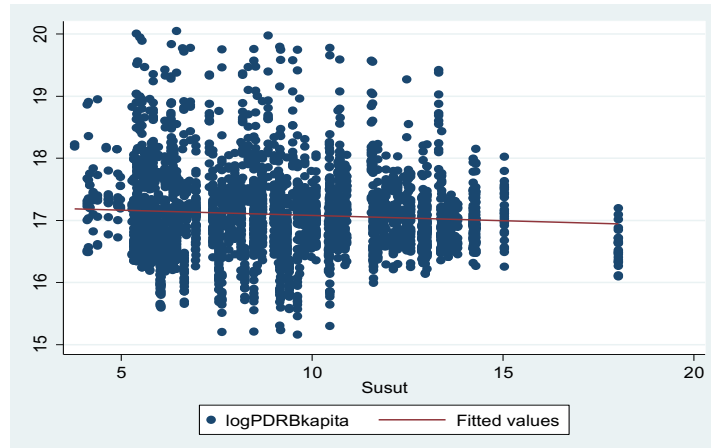

Gambar 4. Scaterplot logPDRBperkapita dengan Susut Jaringan

Pada gambar 2 memperlihatkan bahwa semakin besar susut maka pertumbuhan PDRB per kapita semakin kecil hal tersebut dikarenakan jumlah energi yang bisa digunakan untuk pemakaian listrik semakin besar akibat susut yang mengecil sehingga memicu penggunaan peralatan listrik yang lebih banyak dan menghasilkan output yang lebih baik dari sebelumnya. Kemudian untuk hasil estimasi khususnya secara nasional pada tabel 2 .

Tabel. 2. Hasil Estimasi Pengaruh Elektrifikasi dengan PDRB per kapita dengan Metode FE White's Heteroscedasticity Robust Standard Error

\begin{tabular}{lccc}
\hline \multicolumn{3}{c}{ Variabel Dependen Log PDRBperkapita } \\
\hline Variabel Independen & Model 1 & $\begin{array}{c}\text { Koefisien } \\
\text { Model 2 } \\
\text { (TKSekunder) }\end{array}$ & $\begin{array}{c}\text { Model 3 } \\
\text { (TKTersier) }\end{array}$ \\
\hline Elektrifikasi & $0,0004646^{* *}$ & $0,0005527^{* *}$ & $0,000476^{\star \star}$
\end{tabular}




\begin{tabular}{llll} 
logKons & $0,0640987^{* *}$ & $0,0650328^{* *}$ & $0,0640858^{* *}$ \\
Susut & $0,0026605^{*}$ & $0,0028736^{*}$ & $0,0027908^{*}$ \\
Univ & $-0,000146$ & $-0,0001279$ & $-0,0000576$ \\
logTK & $-0,0093548$ & $-0,00357$ & $-0,0113004$ \\
Tahun & & & \\
2015 & $0,0438038^{* * *}$ & $0,0439067^{* * *}$ & $0,0442327^{* * *}$ \\
2016 & $0,0671147^{* * *}$ & $0,0668108^{* * *}$ & $0,0674335^{* * *}$ \\
2017 & $0,1065844^{* * *}$ & $0,1079711^{* * *}$ & $0,1085667^{* * *}$ \\
2018 & $0,1412291^{* * *}$ & $0,1430139^{* * *}$ & $0,143082^{* * *}$ \\
2019 & $0,1668119^{* * *}$ & $0,1692634^{* * *}$ & $0,16412^{* * *}$ \\
Konstanta & $16,73345^{* * *}$ & $16,6669^{* * *}$ & $16,75581^{* * *}$ \\
\hline Jmh. Observasi & 3049 & 3001 & 3041 \\
RSquared & 0,2039 & 0,1494 & 0,1747 \\
\hline
\end{tabular}

Ket : "signifikan pada level 10\%, ${ }^{* *}$ signifikan pada level $5 \%,{ }^{* * *}$ signifikan pada level $1 \%$

Hasil estimasi dalam penelitian ini sejalan dengan Alam (2018), Cleveland et al. (1997), Schurr (1982), Jorgenson (1984), Lewis \& Severnini (2017), Best \& Burke (2018) bahwa rasio elektrifikasi berpengaruh positif terhadap produktivitas yang dalam penelitian ini didekatkan dengan PDRB per kapita. Adanya akses listrik akan membawa beberapa manfaat, alasan-alasan tersebut dapat meningkatkan produktivitas seseorang seperti adanya penerangan berdasarkan penelitian oleh Dinkelman (2011) yang dapat meningkatkan jumlah jam kerja seseorang, adanya mesin dapat meningkatkan produksi suatu perusahaan dan dapat menurunkan biaya produksi dengan mengganti pekerjaan buruh dengan mesin yaitu yang berkaitan dengan automasi peralatan di pabrik selain itu juga menciptakan sektor bisnis kecil (Akpandjar \& Kitchens, 2017). Peningkatan produksi akibat barang yang dihasilkan dalam waktu tertentu lebih banyak dibandingkan waktu sebelum menggunakan mesin. Dengan meningkatnya efisiensi perusahaan, maka output yang dihasilkan akan lebih cepat dan/atau lebih banyak dari biasanya dengan jumlah input tetap (Kurt \& Kurt, 2015). Selain adanya kehadiran mesin hal tersebut juga sangat didukung oleh peran ICT dan digitalisasi. Digitalisasi dapat meningkatkan produktivitas perusahaan maupun produktivitas tenaga kerja sesuai dengan beberapa penelitian di negara maju (Battisti et al., 2019; Doms et al., 2004; Kroll et al., 2018; Leviakangas, P., Paik, S. M., \& Moon, 2017) secara garis besar bahwa digitalisasi menunjukkan hubungan yang positif dan signifikan terhadap produktivitas tenaga kerja karena dengan menerapkan teknologi ICT, terjadi efisiensi pekerjaan akibat adanya penghematan waktu, energi, dan penggunaan bahan baku dalam proses produksi (Kroll et al., 2018). Kemudian penggunaan listrik dapat memicu Penggunaan digitalisasi/internet (Armey \& Hosman, 2015; Kanagawa \& Nakata, 2008).

Variabel konsumsi listrik mempunyai pengaruh yang positif terhadap PDRB per kapita. Hal ini sesuai dengan penelitian dari Chen (2007). Penelitian mengenai konsumsi listrik sudah banyak dilakukan di dunia. Peran konsumsi listrik terhadap ekonomi bukanlah hal baru, secara garis besar ekonomi juga digerakkan oleh aktivitas konsumsi listrik.

Kemudian variabel susut berpengaruh positif dan signifikan. Dengan adanya susut maka energi yang diproduksi tidak secara maksimal terserap untuk digunakan, semakin besar susut maka energi yang dapat digunakan kecil. Jaringan listrik berfungsi untuk mengangkut energi ke titik konsumen, sedangkan letak pembangkit listrik tidak selalu bersebelahan langsung dengan perumahan atau industri. Secara umum, energi listrik dikonversi pada pusat listrik dengan skala besar yang dekat dengan bahan baku, atau waduk bila merupakan tenaga air. Skala ekonomis sangat penting pada tahap pembangkitan sebelum energi dapat dikirim ke titik konsumsi memalui jaringan transmisi yang teridi dari saluran 
tegangan tinggi. Dengan melihat fenomena tersebut, sistem jaringan listrik selalu kurang dari $100 \%$ dengan energi yang hilang saat mengalir melalui komponen komponen sistem seperti: kabel, trafo, dan lain-lain (Costa-compi, 2018). Banyak penelitian yang mencoba mengurangi adanya efek susut ini salah satu nya oleh Shaw (2009) dan Cronenberg (2012). Dari penjelasan tersebut bahwa penambahan infrastruktur kelistrikan dapat meningkatkan susut akibat bertambahnya peralatan yang mengalami rugi-rugi teknis, selain itu penambahan infrastruktur dapat dipicu akibat meningkatnya jumlah pelanggan sehingga membutuhkan tambahan infrastruktur untuk dapat dialiri tenaga listrik.

Selanjutnya presentase jumlah tenaga kerja berusia 15 tahun yang memiliki ijazah di atas SMA berpegaruh positif dan tidak signifikan di semua model baik menggunakan variabel pertumbuhan produksi listrik maupun menggunakan pertumbuhan konsumsi listrik. penggunaan Sumber Daya Manusia (SDM) yang berkualitas akan meningkatkan output yang dihasilkan karena akan menciptakan invoasi sehingga membuat adanya value added dalam pertumbuhan PDRB. Sejalan dengan penelitian Arif (2014) bahwa untuk mendapatkan SDM yang berkualitas maka dibutuhkan pendidikan dan pelatihan yang memadai pendidikan dan pelatihan dapat dihitung menjadi sebuah bagian dalam investasi untuk meningkatkan output sehingga SDM tersebut dapat meingkatkan produktivitas baik secara persorangan maupun dalam suatu perusahaan, SDM yang inovatif dapat menjadi pusat peningkatan produktivitas (Marrocu \& Paci, 2012).

Variabel pertumbuhan tenaga kerja berpengaruh tidak signifikan terhadap pertumbuhan PDRB per kapita di sektor primer, sekunder maupun tersier. Secara teori produktivitas merupakan sebuah gambaran dari kemampuan seseorang dalam menghasilkan output maka bila output yang dihasilkan seseorang semakin besar maka menunjukkan semakin tinggi tingkat produktivitas orang tersebut, kemungkinan dari hasil estimasi di atas bertambah atau berkurangnya tenaga kerja tidak berpengerah terhadap pertumbuhan PDRB per kapita akibat jumlah tenaga kerja yang tidak produktif dan atau produktivitas yang dalam penelitian ini didekatkan oleh pertumbuhan PDRB per kapita dipicu oleh teknologi (Alexopoulos et al., 2019; Mcguckin, 1998).

Menggunakaan persamaan dan cara estimasi yang sama namun menggunakan data menurut pulau, hasil yang didapatkan adalah sebagai berikut 
Tabel. 3 Matrik Hasil Estimasi Pengaruh Elektrifikasi Terhadap Pertumbuhan PDRB per Kapita per Pulau

\begin{tabular}{|c|c|c|c|c|c|}
\hline Variabel & Sumatera & Jawa Bali & Kalimantan & Sulawesi & MPNT \\
\hline Elektrifikasi & $\begin{array}{l}\text { Signifikan (+) } \\
\text { Adanya elektrifikasi } \\
\text { dapat digunakan oleh } \\
\text { masyarakat sebagai } \\
\text { input produksi sehingga } \\
\text { menghasilkan output } \\
\text { yang lebih baik. Di tahun } \\
2014 \text { rata rata } \\
\text { elektrifikasi di Pulau } \\
\text { Sumatera sebesar } 80 \% \\
\text { dan pada tahun } 2019 \\
\text { eletrifikasi di Pulau } \\
\text { Sumatera sebesar } 98 \% \\
\text { dari periode tersebut } \\
\text { pada tahun } 2019 \text { terjadi } \\
\text { kenaikan PDRB per } \\
\text { kapita sebesar } 22,56 \% \\
\text { dari PDRB per kapita } \\
\text { tahun } 2014\end{array}$ & $\begin{array}{l}\text { Belum Signifikan } \\
\text { Pada Pulau Jawa } \\
\text { Bali tingkat } \\
\text { elektrifikasi di } \\
\text { kabupaten dan kota } \\
\text { pada tahun } 2014 \text { - } \\
2019 \text { sudah banyak } \\
\text { yang mencapai } 90 \% \\
\text { sehingga } \\
\text { pergerakan } \\
\text { elektrifikasi tidak } \\
\text { terlalu berpengaruh } \\
\text { terhadap PDRB per } \\
\text { kapita }\end{array}$ & $\begin{array}{l}\text { Signifikan (+) } \\
\text { Hal ini kemungkinan } \\
\text { dikarenakan pada } \\
\text { Pulau Kalimantan, , } \\
\text { cukup banyak } \\
\text { daerah pada Pulau } \\
\text { Kalimantan memiliki } \\
\text { tingkat elektrifikasi } \\
\text { yang rendah pada } \\
\text { tahun } 2014 \text { dengan } \\
\text { rata-rata elektrifikasi } \\
\text { sebesar } 72 \%, \text { dan } \\
\text { pada tahun } 2019 \\
\text { elektrifikasi minimal } \\
\text { sebesar } 82 \%, \\
\text { adanya elektrifikasi } \\
\text { secara konstan } \\
\text { meningkatkan } \\
\text { PDRB per kapita di } \\
\text { kabupaten dan kota } \\
\text { pada Pulau } \\
\text { Kalimantan }\end{array}$ & $\begin{array}{l}\text { Belum Signfikan } \\
\text { PDRB dan } \\
\text { elektrifikasi di Pulau } \\
\text { Sulawesi meningkat } \\
\text { setiap tahunnya } \\
\text { namun di beberapa } \\
\text { kabupaten, } \\
\text { peningkatan PDRB } \\
\text { tidak sebesar } \\
\text { peningkatan jumlah } \\
\text { penduduk sehingga } \\
\text { PDRB per kapita di } \\
\text { beberapa kabupaten } \\
\text { tersebut mengalami } \\
\text { penurunan akibat } \\
\text { pemotongan "kue” } \\
\text { PDRB yang } \\
\text { semakin banyak, } \\
\text { sehingga } \\
\text { mrnyebabkan data } \\
\text { cukup berfluktuatif } \\
\text { selain itu juga dapat } \\
\text { dipicu kualitas } \\
\text { elektrifikasi yang } \\
\text { dihasilkan tidak baik } \\
\text { sehingga } \\
\text { penggunaan tidak } \\
\text { maksimal }\end{array}$ & $\begin{array}{l}\text { Belum Signifikan } \\
\text { Sama hal nya } \\
\text { dengan Sulawesi, } \\
\text { jumlah PDRB setiap } \\
\text { tahun mengalami } \\
\text { kenaikan namun } \\
\text { tidak bisa } \\
\text { mengimbangi } \\
\text { kenaikan jumlah } \\
\text { penduduk sehingga } \\
\text { beberapa kabupaten } \\
\text { memiki PDRB per } \\
\text { kapita yang } \\
\text { menurun dan } \\
\text { mengakibtkan data } \\
\text { yang dihasilkan } \\
\text { cukup berfluktuatif } \\
\text { selain itu } \\
\text { kemungkinan juga } \\
\text { dapat diakibatkan } \\
\text { kualitas listrik } \\
\text { kurang baik akibat } \\
\text { jauhnya jarak } \\
\text { penyaluran listrik, }\end{array}$ \\
\hline
\end{tabular}




\begin{tabular}{|c|c|c|c|c|c|}
\hline Variabel & Sumatera & Jawa Bali & Kalimantan & Sulawesi & MPNT \\
\hline logKons & $\begin{array}{l}\text { Belum Signifikan } \\
\text { adanya elektrifikasi } \\
\text { seharusnya memicu } \\
\text { pertumbuhan konsumsi } \\
\text { listrik, pada Pulau } \\
\text { Sumatera merupakan } \\
\text { kedua terbesar } \\
\text { konsumsi listrik di } \\
\text { Indonesia, namun } \\
\text { kemungkinan } \\
\text { penggunaan energi } \\
\text { listrik tidak digunakan } \\
\text { untuk produktivitas }\end{array}$ & $\begin{array}{l}\text { Siginifikan (+) } \\
\text { Memiliki Tingkat } \\
\text { konsumsi listrik } \\
\text { terbesar di } \\
\text { Indonesia, pada } \\
\text { pulau ini listrik } \\
\text { sudah menjadi } \\
\text { kebutuhan } \\
\text { kehidupan sehari } \\
\text { hari selain itu juga } \\
\text { sangat didukung } \\
\text { oleh sektor industri } \\
\text { dan sektor bisnis } \\
\text { yang dominan di } \\
\text { pulau jawa }\end{array}$ & $\begin{array}{l}\text { Signifikan (+) } \\
\text { adanya elektrifikasi } \\
\text { meningkatkan } \\
\text { penggunaan listrik } \\
\text { khususnya hampir di } \\
\text { setiap kabupaten } \\
\text { dan kota di } \\
\text { Kalimantan } \\
\text { kemungkinan hal } \\
\text { tersebut dipicu } \\
\text { akibat kualitas listrik } \\
\text { yang cukup bagus }\end{array}$ & $\begin{array}{l}\text { Belum Signifikan } \\
\text { Dapat terjadi akibat } \\
\text { elektrifikasi yang } \\
\text { tidak baik seperti } \\
\text { kualitas listrik yang } \\
\text { buruk sehingga } \\
\text { tidak efektif } \\
\text { berperan dalam } \\
\text { pemakaian } \\
\text { peralatan listrik atau } \\
\text { dapat disebabkan } \\
\text { pemakaian listrik } \\
\text { yang tidak efektif } \\
\text { atau tidak produktif } \\
\text { sehingga tidak } \\
\text { menunjang ke } \\
\text { PDRB per kapita }\end{array}$ & $\begin{array}{l}\text { Belum Signifikan } \\
\text { dapat disebabkan } \\
\text { karena kualitas } \\
\text { listrik yang diberikan } \\
\text { tidak sesuai } \\
\text { harapan maupun } \\
\text { penggunaan listrik } \\
\text { yang tidak } \\
\text { digunakan secara } \\
\text { baik atau produktif }\end{array}$ \\
\hline Susut & $\begin{array}{l}\text { Signifikan (+) } \\
\text { Adanya penambahan } \\
\text { pelanggan sehingga } \\
\text { membutuhkan asset } \\
\text { baru yang menghasilkan } \\
\text { rugi rugi teknis atau } \\
\text { susut teknis selain itu } \\
\text { dapat juga diakibatkan } \\
\text { pencurian listrik yang } \\
\text { digunakan oleh } \\
\text { masyarakat sehingga } \\
\text { dengan memanfaatkan } \\
\text { keadaan tersebut } \\
\text { meningkatkan PDRB per } \\
\text { kapita }\end{array}$ & $\begin{array}{l}\text { Tidak Signifikan } \\
\text { Realisasi susut } \\
\text { pada tahun } 2014- \\
2019 \text { di Pulau Jawa } \\
\text { sudah sangat kecil } \\
\text { pada tahun } 2014 \\
\text { sebesar } 8,13 \% \text { dan } \\
\text { di tahun } 2019 \\
\text { sebesar } 4,26 \% \text {. } \\
\text { Selain } \\
\text { pergerakannya, } \\
\text { jumlah susut dapat } \\
\text { naik juga akibat } \\
\text { penambahan } \\
\text { pelanggan }\end{array}$ & $\begin{array}{l}\text { Signifikan (+) } \\
\text { Pada Pulau } \\
\text { Kalimantan } \\
\text { pengaruh susut } \\
\text { jaringan } \\
\text { kemungkinan } \\
\text { diakibatkan adanya } \\
\text { penambahan } \\
\text { pelanggan dan } \\
\text { asset jaringan akibat } \\
\text { efek dari } \\
\text { elektrifikasi, } \\
\text { meskipun susut } \\
\text { jaringan } \\
\text { berpengaruh negatif } \\
\text { terhadap }\end{array}$ & $\begin{array}{l}\text { Belum Signifikan } \\
\text { Dapat diartikan } \\
\text { bahwa penambahan } \\
\text { susut atau } \\
\text { pengurangan susut } \\
\text { tidak berpengaruh } \\
\text { terhadap } \\
\text { pertumbuhan PDRB } \\
\text { per kapita, hal } \\
\text { tersebut dapat } \\
\text { terjadi bila kondisi } \\
\text { susut sangat } \\
\text { berfluktuatif } \\
\text { sehingga tidak } \\
\text { dapat terhubung }\end{array}$ & $\begin{array}{l}\text { Belum Signifikan } \\
\text { Variabel susut } \\
\text { jaringan belum } \\
\text { signifikan terhadap } \\
\text { pertumbuhan PDRB } \\
\text { per kapita } \\
\text { kemungkinan juga } \\
\text { dipicu akibat } \\
\text { inkonsistensi atau } \\
\text { variabel susut } \\
\text { jaringan sangat } \\
\text { berfluktuatif } \\
\text { sehingga sulit } \\
\text { didefinisikan } \\
\text { pengaruhnya } \\
\text { terhadap }\end{array}$ \\
\hline
\end{tabular}




\begin{tabular}{|c|c|c|c|c|c|}
\hline Variabel & Sumatera & Jawa Bali & Kalimantan & Sulawesi & MPNT \\
\hline & & & $\begin{array}{l}\text { pertumbuhan PDRB } \\
\text { per kapita, }\end{array}$ & $\begin{array}{l}\text { langsung dengan } \\
\text { PDRB per kapita, }\end{array}$ & $\begin{array}{l}\text { pertumbuhan PDRB } \\
\text { per kapita. }\end{array}$ \\
\hline
\end{tabular}
Belum Signifikan

kemungkinan akibat jumlah tenaga kerja yang bersifat fluktuatif di setiap kabupaten dan kota yang menyebabkan variabel tersebut tidak signifikan, secara teori adanya jumlah tenga kerja yang terdidik akan memicu penggunaan alatalat kerja atau produksi yang bersifat digital atau bersumber dari listrik, penggunaan peralatan - peralatan tersebut seperti yang dijelaskan sebelumnya akan menghasilkan manfaat dan berdampak baik terhadap produktivitas yang pada penelitian ini didekatkan oleh PDRB per kapita.

TKx Sumatera, Jawa Bali, Kalimantan, Sulawesi tidak signifikan namun Signifikan (-) pada sektor Primer khususnya di MPNT

Pada kepulauan Maluku, Papua dan Nusa Tenggara secara agregat tenaga kerja paling dominan adalah dari sektor primer, pada tahun 2014 sebesar $56 \%$ dari total tenaga kerja, namun dari tahun ke tahun jumlah tenaga kerja pada sektor primer di MPNT mengalami penurunan hingga di tahun 2019 proporsi tenaga kerja sektor primer sebesar $45 \%$ dari total tenaga kerja dan terjadi peningkatan di sektor sekunder dan sektor tersier hal tersebut diakibatkan pergeseran tenaga kerja yang sebelumnya sektor primer ke sektor sekunder dan sektor tersier. Sektor primes relative memiliki tenaga kerja yang banyak namun produktivitasnya rendah dibandingkan sektor lainnya (Cahyo, 2020). Sedangkan pada kategori pulau lainnya dari hasil estimasi tidak signifikan terhadap pertumbuhan PDRB per kapita hal tersebut kemungkinan perbedaan karakteristik tiap daerah dan tiap tahun yang bervariasi dan berfluktuatif

Kemudian hasil estimasi pada pembagian daerah dibandingkan pada tabel berikut:

Tabel. 4 Matrik Hasil Estimasi Pembagian Daerah Kabupaten dan Kota

\begin{tabular}{cll}
\hline Variabel & \multicolumn{1}{c}{ Kabupaten } & \\
\hline Elektrifikasi & Signifikan (+) & Tidak Signifikan \\
& Cukup banyak kabupaten yang elektrifikasinya masih & Hal tersebut diakibatkan karena cukup banyak daerah yang \\
& rendah pada tahun 2014 - 2019, sehingga adanya & berstatus kota telah memiliki elektrifikasi tinggi dan sudah \\
& peningkatan akses listrik pada daerah tersebut cukup & 100\% pada periode 2014-2019 sehingga elektrifikasi tidak \\
& berdampak terhadap pertumbuhan PDRB per kapita & terlalu terlihat atau signifikan \\
\hline logKons & Tidak Signifikan & Signifikan (+) \\
& kemungkinan diakibatkan masyarakat pada daerah & Akibat adanya akses listrik yang cukup tinggi, masyarakat baik \\
& kabupaten belum mempersiapkan peralatan-peralatan & perusahaan maupun perorangan sudah mempunyai atau \\
& yang menggunakan listrik sebagai sumbernya dan & menggunakan peralatan - peralatan yang bersumber dari
\end{tabular}




\begin{tabular}{|c|c|c|}
\hline Variabel & Kabupaten & Kota \\
\hline & $\begin{array}{l}\text { belum digunakan secara efektif untuk menunjang } \\
\text { produktivitas. Selain itu dapat juga diakibatkan kualitas } \\
\text { listrik yang belum memadai sehingga listrik yang } \\
\text { digunakan tidak efektif }\end{array}$ & $\begin{array}{l}\text { listrik, dimana peralatan tersebut sangat menunjang } \\
\text { produktivitas dan tidak terlepas dari kebutuhan sehari-hari. }\end{array}$ \\
\hline Susut & $\begin{array}{l}\text { Signifikan (+) } \\
\text { Hal ini dimungkinkan akibat penambahan aset yang } \\
\text { cukup banyak untuk menjangkau ujung daerah } \\
\text { sehingga menyebabkan susut teknis (energi listrik yang } \\
\text { hilang akibat karakteristik peralatan) dan dapat juga } \\
\text { disebabkan pencurian listrik yang energi listrik tersebut } \\
\text { tidak terakumulasi kedalam konsumsi listrik namun } \\
\text { masyarakat menggunakan listrik illegal tersebut untuk } \\
\text { keperluan produktivitas. }\end{array}$ & $\begin{array}{l}\text { Tidak Signifikan } \\
\text { Penambahan atau pengurangan susut jaringan tidak } \\
\text { berpengaruh terhadap pertubuhan PDRB per kapita, secara } \\
\text { teori semakin rendahnya susut maka pertumbuhan PDRB per } \\
\text { kapita akan lebih baik, hal ini kemungkinan akibat masih cukup } \\
\text { banyaknya pengembangan asset jaringan untuk menjangkau } \\
\text { penduduk daerah kota selain itu dapat juga akibat tingkat } \\
\text { pencurian listrik, sehingga data yang dihasilkan cukup fluktuatif } \\
\text { antara kota satu dengan kota yang lainnya }\end{array}$ \\
\hline Univ & $\begin{array}{l}\text { Tidak Signifikan } \\
\text { Penambahan atau pengurangan presentase jumlah tena } \\
\text { terhadap PDRB per kapita, hal ini kemungkinan karakter } \\
\text { Pendidikan yang cukup tinggi pada tahun } 2014-2019 \mathrm{~s} \\
\text { tenaga kerja memiliki ijazah di atas SMA sulit dideteksi a }\end{array}$ & $\begin{array}{l}\text { a kerja memiliki ijazah di atas SMA keatas tidak berpengaruh } \\
\text { tik setiap kabupaten dan kota yang berbeda - beda, tingkat } \\
\text { hingga penambahan atau pengurangan presentase jumlah } \\
\text { anya pengaruh terhadap pertumbuhan PDRB per kapita. }\end{array}$ \\
\hline LogTKx & $\begin{array}{l}\text { Signifikan (-) sektor Primer } \\
\text { Tenaga kerja pada sektor primer di daerah kabupaten } \\
\text { cukup tinggi, secara agregat tenaga kerja pada sektor } \\
\text { primer sebesar } 42 \% \text { dari total tenaga kerja. Pengaruh } \\
\text { negative yang ditimbulkan secara agregat terlihat } \\
\text { tenaga kerja pada sektor primer mengalami penurunan, } \\
\text { sedangkan pada sektor sekunder dan tersier terjadi } \\
\text { peningkatan tenaga kerja, trend menurun tersebut di } \\
\text { juga terjadi di beberapa negara berkembang karena } \\
\text { konsekuensi dari peningkatan kontribusi dari sektor non } \\
\text { agrikultur (Briones \& Felipe, 2013; Cahyo, 2020). }\end{array}$ & $\begin{array}{l}\text { Tidak Signifikan } \\
\text { Adanya tenga kerja dari sektor primer, sekunder maupun } \\
\text { tersier tidak dapat mencerminkan pertumbuhan PDRB per } \\
\text { kapita, hal tersebut kemungkinan dipicu akibat perbedaan } \\
\text { karakteristik setiap daerah sehingga hasil yang dihasilkan } \\
\text { cukup berfluktuatif, dalam teori produksi penambahan tenaga } \\
\text { kerja akan menambah produktifitas selama faktor produksi } \\
\text { tersedia, namun selain itu adanya teknologi dapat } \\
\text { menggantikan tenaga kerja untuk menghasilkan output, } \\
\text { sehingga tenaga kerja yang diperlukan hanya beberapa saja }\end{array}$ \\
\hline
\end{tabular}




\section{SIMPULAN DAN SARAN}

Berdasarkan hasil estimasi, maka dapat diambil kesimpulan:

a. Secara nasional elektrifikasi berpengaruh positif dan signifikan terhadap pertumbuhan PDRB per kapita pada tahun $2014-2019$, hasil tersebut sesuai dengan hipotesis yang diajukan yaitu elektrifikasi berpengaruh positif dan signifikan terhadap PDRB per kapita. Kemudian bila dikelompokan menurut pulau, elektrifikasi berpengaruh positif dan signifikan terhadap PDRB per kapita di tahun 2014-2019 pada Pulau Sumatera, Kalimantan, dan belum signifikan pada pulau Jawa-Bali, Sulawesi dan MPNT.

b. Pertumbuhan konsumsi listrik berpengaruh positif dan signifikan terhadap PDRB per kapita secara nasional pada tahun 2014-2019, sedangkan variabel pertumbuhan konsumsi listrik berpengaruh positif dan signifikan terhadap PDRB per kapita tahun 2014-2019 di Pulau Jawa-Bali dan Kalimantan namun belum signifikan terhadap PDRB per kapita di pulau Sumatera, Sulawesi dan MPNT

Berdasarkan hasil estimasi dalam penelitian ini :

a. Pemerintah terus mengupayakan pemenuhan elektrifikasi secara nasional terutama untuk daerahdaerah yang belum mencapai $100 \%$

dan belum optimal seperti pulau Sulawesi dan kepulauan Maluku, Papua dan Nusa Tenggara

b. Pemerintah agar menyediakan tenaga listrik yang reliabel, andal dan berkualitas baik sehingga penggunaan tenaga listrik dapat dilakukan secara maksimal dan efisien oleh masyarakat terutama untuk Pulau Sumatera, Sulawesi dan MPNT serta masyarakat agar dapat mengoptimalkan penggunaan listrik kearah yang lebih produktif agar dapat meningkatkan PDRB per kapita.

\section{DAFTAR PUSTAKA}

Akpandjar, G., \& Kitchens, C. (2017). From Darkness to Light: The effect of electrification in Ghana, $2000-2010$.

Alam, M. (2018). The Nexus Between Access to Electricity and Labour Productivity in Developing Countries. Energy Policy, 122, 715-726.

Alexopoulos, Michelle, Cohen, \& Jon. (2019). Will the New Technologies Turn the Page on U.S. Productivity Growth. Economics Letters, 175, 1923.

Arif, M. (2014). Pengaruh Pendidikan Terhadap Pendapatan Domestik Regional Bruto di Indonesia. Signifikan, 3(1).

Armey, L. E., \& Hosman, L. (2015). The Centrality of Electricity to ICT Use in Low-Income Countries. Telecommunications Policy.

Barnes, \& Binswanger. (1986). Impact of Rural Electrification and Infrastructure on Agricultural Changes, 1966-1980. Economic and Political, 21(1).

Battisti, M., Belloc, F., \& Del Gatto, M. (2019). Labor Productivity and Firmlevel TFP with Technology-specific Production Functions. Review of Economic Dynamics, 35, 283-300.

Best, R., \& Burke, P. J. (2018). Electricity Availability: A Precondition for Faster Economic Growth? Energy Economics, 74, 321-329.

Briones, R., \& Felipe, J. (2013). Agriculture and structural transformation in developing Asia: Review and outlook. $A D B$ Economics Working Paper Series, 363(363), 1-39.

Burke, P. J., \& Kurniawati, S. (2018). Electricity Subsidy Reform in Indonesia: Demand-side Effects on Electricity Use. Energy Policy, 116, $410-421$.

Cahyo. (2020). Structural Transformation of Agriculture and Poverty in Indonesia. Wiga: Jurnal Penelitian IImu Ekonomi, 10(1).

Chen. (2007). The Relationship Between GDP and Electricity Consuption in 10 Asian Countries. Energy Policy, 35, 2611-2621. 
Cleveland, C. J., Costanza, R., Hall, C. A., \& Kaufmann, R. (1997). Energy and the US Economy: a Biophysical Perspective. Int. Libr. Crit. Writ. Econ., 75, 295-302.

Costa-compi. (2018). The Economic Impacts of Electricity Losses. Energy Economics, 75, 309-322.

Cronenberg. (2012). How do the Benefits from Active Demand Vary? A Comparison of Four EU Countries. Energy Conference and Exhibition (ENERGYCON), 693-700.

Dinkelman, T. (2011). The Effects of Rural Electrification on Employment: New Evidence from South Africa. American Economic Review, 101, 3078-3108.

Doms, M. E., Jarmin, R. S., \& Klimek, S. D. (2004). Information technology investment and firm performance in US retail trade. Economics of Innovation and New Technology, 13(7), 595-613.

Jajri, I., \& Ismail, R. (2010). Impact of Labour Quality on Labour Productivity and Economic Growth. Africa Journal of Business Management VI, 4(4), 486 -495 .

Jorgenson, D. . (1984). The role of energy in productivity growth. Energy J, 5(3), 11-26.

Kanagawa, M., \& Nakata, T. (2008). Assessment of Access to Electricity and the Socio - Economic Impacts in Rural Areas of Developing Countries. Energy Policy, 36, 2016 - 2029.

Kassem, D. (2018). Does Electrification Cause Industrial Development? Grid Expansion and Firm Turnover in Indonesia (No. 052; CRC TR 224).

Khandker. (2013). Welfare Impacts of Rural Electrification: A Panel Data Analysis from Vietnam 659-692. Economic Development and Cultural Change, 61(3), 659-692.

Kroll, H., Horvat, D., \& Jäger, A. (2018). Effects of automatisation and digitalisation on manufacturing companies' production efficiency and innovation performance. Fraunhofer ISI Discussion Papers - Innovation Systems and Policy Analysis, 58.

Kurt, S., \& Kurt, U. (2015). Innovation and
Labour Productivity in Brics Countries: Panel Causality and Co-integration. Procedia: Social and Behavioral Sciences, 195, $1295-1302$.

Kyriakarakos, G., Balafoutis, A. T., \& Bochtis, D. (2020). Proposing a paradigm shift in rural electrification investments in Sub-Saharan Africa through Agriculture. Sustainability (Switzerland), 12(8). https://doi.org/10.3390/SU12083096

Lagenjik, A. (2008). Survival Guide For Scientists. Amsterdam: Amsterdam University Press.

Leviakangas, P., Paik, S. M., \& Moon, S. (2017). Keeping up with the pace of digitization: the case of the Australian construction industry. Technology in Society, 50, 33-43.

Lewis, J., \& Severnini, E. (2017). Short and Long Run Impacts of Rural Electrification: Evidence from the Historical Rollout of the U.S. Power Grid.

Lipscomb. (2013). Development Effects of Electrification: Evidence from the Topographic Placement of Hydropower Plant in Brazil. American Economic Journal: Applied Economics, 5(2), 200-231.

Marrocu, E., \& Paci, R. (2012). Education or Creativity: What Matters Most for Economic Performance? Economic Geography.

Mcguckin. (1998). The Effect of Technology Use On Productivity Growth. Economics of Innovation and New Technology, 7(1), 1-26.

Schurr, S. . (1982). Energy Efficiency and Productive Efficiency: Some Thoughts Based on American Experience. Energy J, 3-14.

Sebastian. (2020). Electricity Access and Structural Transformation Evidence from Brazil's Electrification (Policy Research Working Paper).

Shaw. (2009). The Value of Reducing Distribution Losses by Domestic Load-Shifting: a Network Perspective. Energy Policy, 37(8), 3159-3167.

Stern, D. I., \& Cleveland, C. . (2004). Energy and Economic Growth (No. 0410). 
p-ISSN : 2599-1418

Jurnal Pendidikan Ekonomi Undiksha

e-ISSN : 2599-1426

Vol. 13 No. 1 (2021)

Suryadi. (2001). Kontribusi Total

Produktivitas terhadap Perekonomian

DKI Jakarta, Infomet. Cestar Bekerja Sama Dengan BPS, 1(2).

Suryani, E. (2006). Analisis Total Faktor Produktivitas dan Pertumbuhan Ekonomi Sumatera Selatan. Jurnal Ekonomi Pembangunan, 4(2), 93105. 